\title{
Improved Camptothecin Production of Camptotheca Acuminata on Hydroponic Medium Supplemented with Various Chemicals
}

\section{Qing-qian ZENG ${ }^{1}$, Lin JIANG ${ }^{2}$, Long-ping ZHU ${ }^{2}$, Hai ZHENG ${ }^{1}$ and De-po YANG ${ }^{2}$}

${ }^{1}$ Guangdong Research Institute of Traditional Chinese Medicine, Guangzhou, Guangdong Province, P.R. China

${ }^{2}$ Laboratory of Pharmacognosy \& Natural Medicinal Chemistry, School of Pharmaceutical Sciences, Sun Yat-sen University, Guangzhou, Guangdong Province, P.R. China

${ }^{*}$ Corresponding author

Keywords: Organic acid, Metal ion, Camptothecin yield, Hydroponic culture.

\begin{abstract}
A Hydroponic culture was conducted to determine the effect of organic acids and metal ions on plant growth, camptothecin concentrations and yield of Camptotheca acuminata, in an effort to increase the camptothecin yield by artificial cultivation. For maximal camptothecin production, increase of maleic acid to $1 \mu \mathrm{mol} / \mathrm{L}$, malic acid to $0.5 \mu \mathrm{mol} / \mathrm{L}$ or malonic acid to $5 \mu \mathrm{mol} / \mathrm{L}$ on Hoagland nutrition solution medium resulted in 1.418, 2.371 and 1.535 fold increase of camptothecin production, respectively, and increase of metal ions both $\mathrm{La}^{3+}$ and $\mathrm{Nd}^{3+}$ to $5 \mu \mathrm{mol} / \mathrm{L}$ or $\mathrm{Ce}^{3+}$ to $1 \mu \mathrm{mol} / \mathrm{L}$ resulted in $1.832,1.748$ and 1.822 fold production of camptothecin. These preliminary results suggested that, the application of organic acids and metal ions may be a useful and feasible method to increase camptothecin production in Camptotheca acuminata. Further research in optimizing the culture conditions of Camptotheca acuminata might permit their application for the production of camptothecin.
\end{abstract}

\section{Introduction}

Camptothecin (CPT) inhibits the growth of tumor cells by blocking the topoisomerase[1]. Its semi-synthetic derivatives, Topotecan (TPT) and Irinotecan (CPT-11), are widely used as the standard chemotherapy drugs in patients with ovarian and colaoectal cancer[2]. The tremendous market demand for the anti-cancer drugs, requires increased production of their precursor CPT. Therefore CPT is a valuable starting material for the production of TPT and CPT-11 and becoming increasingly important[3].

CPT was first isolated from the plant Chinese Camptotheca acuminata[4]. The contents of CPT in raw materials are very low ranging from $0.004 \%$ to $0.4 \%$ of dry weight $[3,5,6]$. Additionally, the production of CPT in plant cell and tissue cultures, and hair roots are lower than that in original plant materials, ranging from $0.0025 \%$ to $0.236 \%[3,7]$. To maximize the product yields, it is therefore highly desirable to optimize the plant cultures.

Application of various exogenous chemicals to culture medium have been shown to increase the yield of the desired secondary metabolite product in plant tissue cultures [8,9] or endophytic fungi submerged culture[10]. Some heavy metal and rare earth element ions are often used to trigger secondary metabolite production and improve the 
plant growth under tissue culture conditions[11,12,13,14]. Some organic acid, such as malic acid, have been applied to improved alkaloid production in Catharanthus rospension cell cultures[15]. Increased alkaloid content was also reported in Catharanthus plants by application of succinic acid[16]. Whether some of these factors could play similar roles in increasing the accumulation of secondary metabolites in field plant is unknown. The objectives of this study were to examine and find effective elicitors to improve CPT production and plant growth of $\mathrm{C}$. acuminata by changing the hydroponic culture conditions.

\section{Materials and Methods}

Growth and treatment of seedlings. The seedlings of C. acuminata were propagated using cuttings from expanding shoot tips of single tree and cultured in a specimen garden at the Guangdong Research Institute of Traditional Chinese Medicine (Guangzhou, China). After 60 days, the rooted seedlings were selected uniformity. The seedlings were fixed in foam pan with a hole in it and placed in a hydroponic plastics tray filled with 5 liters of Hoagland nutrition solution ${ }^{[17]}$ adjusted to $\mathrm{pH}$ 6.0. New roots were developed in 30 days after planting, which were suitable to aquiculture. At that time, three type elicitors were added into Hoagland nutrition solution as treatments based on previous studies ${ }^{[11,12,15,18,19]}$, including of $0.2 \mu \mathrm{mol} / \mathrm{L}$ organic acid: maleic acid, malic acid and malonic acid, $1 \mu \mathrm{mol} / \mathrm{L}$ heavy metal ion: $\mathrm{CuCl}_{2}, \mathrm{ZnSO}_{4}$ and $\mathrm{Ag}_{2} \mathrm{SO}_{4}$, $1 \mu \mathrm{mol} / \mathrm{L}$ rare earth element ion: $\mathrm{LaCl}_{3}, \mathrm{CeCl}_{3}$ and $\mathrm{NdCl}_{3}$, normal concentration of Hoagland nutrition solution served as control. All chemicals used in the experiment were at least AR and mostly available from Guangzhou Chemical Reagent Factory, China. The hydroponic culture solutions were replaced every two weeks. The aquiculture was maintained at $(25 \pm 1)^{\circ} \mathrm{C}$ in a grass greenhouse with air conditioning to ensure the consistent growth of the seedlings. After 90 days of treatment, the seedlings were harvested and oven-dried at $70^{\circ} \mathrm{C}$ for 48 hours. The dry weight of the whole seedlings was used as indicators of plant growth and was analyzed for the concentration of CPT. The oven-dried plant materials were ground to fine powder and stored in plastic bags for further chemical analyses of CPT concentrations. All experiments were independently performed in quadruplicate.

Screening optimal treatment concentration. After confirming that CPT was produced under the hydroponic culture solutions mentioned above, we then studied the dosage effects of organic acids and metal ions on C. acuminata growth and CPT production in the following manner. Ninety seedlings having new root system grown in Hoagland nutrition solution were chosen and divided equally into six groups, with each group assigned to fifteen hydroponic plastic trays. In each group, seedlings were assigned randomly to the following concentrations: maleic acid, malic acid and malonic acid level of $0.05,0.1,0.5,1$ and $2 \mu \mathrm{mol} / \mathrm{L} ; \mathrm{LaCl}_{3}, \mathrm{CeCl}_{3}$ and $\mathrm{NdCl}_{3}$ level of $0.5,1,5,10$ and $20 \mu \mathrm{mol} / \mathrm{L}$. Each treatment in each group was performed in quadruplicate. Seedlings were grown under conditions mentioned above and the harvests were performed in a similar manner.

Extraction of alkaloids. About $0.4 \mathrm{~g}$ ground-dried materials were extracted with 25 $\mathrm{ml} 75 \%$ ethanol in $50 \mathrm{ml}$ conical bottles. After weighed, the conical bottles were put into an ultrasonic bath under $50^{\circ} \mathrm{C}$ for $10 \mathrm{~min}$. When the solutions were cold to room temperature, the lost solutions were made up with $75 \%$ ethanol. This procedure extracts about $94 \%$ of CPT from aqueous solutions. The extract was filtered through $0.45 \mu \mathrm{m}$ 
membrane filter and $10 \mu \mathrm{l}$ of the filtered extract was used to analyze the CPT content with high-performance liquid chromatography (HPLC).

HPLC analysis. CPT content was analyzed with a HPLC system (Waters, USA) including a high pressure pump (Waters 2695) with a controller and a Photo Diode Array Detector (Waters 2996). $10 \mu \mathrm{l}$ extract was applied onto a C-18 column $(5 \mu \mathrm{m}$, $4.6 \times 250 \mathrm{~mm})$ and was eluted with an isocratic mobile phase acetonitrile-water (30:70) at a flow rate of $1 \mathrm{ml} / \mathrm{min}$, and detected at $254 \mathrm{~nm}$. A standard curve $(0.005-0.025 \mathrm{mg} / \mathrm{ml})$ was obtained using authentic CPT samples. The authentic CPT was purchased from National Institute for the Control of Pharmaceutical and Biological Products, China. The retention time for CPT was $11.8 \mathrm{~min}$. The peak area was quantified with the external standard method. Samples were processed and analyzed in quadruplicate. CPT concentrations (\% dry weigh) were obtained on dry weight basis. CPT yields (mg) were calculated from the whole plant CPT concentrations and the total dry seedlings weights.

Statistical analysis. Statistical analysis was performed using one way analysis of variance (ANOVA) followed by Duncan's Multiple Range Test (DMRT). The values are mean $\pm \mathrm{SE}$ for quadruplicate samples in each group. Probability value $\mathrm{P}$ less than 0.05 was considered significant. Analysis was carried out with SPSS software, version 14.0 for windows.

\section{Results}

Effects of various organic acids and metal ions on CPT production and plant growth. There was a significant interaction between chemical additions to Hoagland nutrition solution on CPT concentration, plant weight and CPT yield. After 90 days of treatment, supplementation of Hoagland's Solution with malonic acid and $\mathrm{Nd}^{3+}$ did not change the plant weight evidently, but significantly affected seedlings CPT concentrations, resulted in a maximum CPT accumulation of 131.480 and $118.650 \mathrm{mg} / \mathrm{seedling}$, respectively, which was 2.1 and 1.9 fold increase compared with that with no supplements (Table 1). The increment achieved after supplemented with maleic acid, malic acid, $\mathrm{Ce}^{3+}$ and $\mathrm{La}^{3+}$ were somehow lower than that obtained after supplementing malonic acid or $\mathrm{Nd}^{3+}$. Supplementing other metal ions increased CPT content but decreased plant weight, which was not helpful for achieving high total CPT yield.

Table 1. CPT production and plant growth of $C$. acuminata treated with different treatment of organic acids and metal ions.

\begin{tabular}{|c|c|c|c|c|}
\hline Treatment & $\begin{array}{c}\text { Concentration } \\
(\mu \mathrm{mol} / \mathrm{L})\end{array}$ & $\begin{array}{c}\text { CPT } \\
(\% \text { DW })\end{array}$ & $\begin{array}{l}\text { Plant weight } \\
\text { (g DW) }\end{array}$ & $\begin{array}{c}\text { CPT yield } \\
\text { (mg/seedling) }\end{array}$ \\
\hline Control & 0 & $0.105 \pm 0.004 \mathrm{~g}$ & $58.133 \pm 0.213 \mathrm{e}$ & $\begin{array}{c}61.156 \pm 3.167 \\
\mathrm{fg}\end{array}$ \\
\hline Maleic acid & 0.2 & $0.123 \pm 0.006 \mathrm{ef}$ & $60.439 \pm 0.583 \mathrm{~d}$ & $\begin{array}{c}74.401 \pm 4.011 \\
\mathrm{~d}\end{array}$ \\
\hline Malic acid & 0.2 & $0.117 \pm 0.007 \mathrm{f}$ & $66.277 \pm 1.013 \mathrm{a}$ & $\begin{array}{c}77.455 \pm 3.236 \\
\mathrm{~d}\end{array}$ \\
\hline $\begin{array}{l}\text { Malonic } \\
\text { acid }\end{array}$ & 0.2 & $0.205 \pm 0.004 \mathrm{a}$ & $64.220 \pm 0.702 b c$ & $\begin{array}{c}131.480 \pm 1.587 \\
\mathrm{a}\end{array}$ \\
\hline $\mathrm{Cu} 2+$ & 1 & $0.130 \pm 0.003 \mathrm{e}$ & $46.311 \pm 1.225 \mathrm{~g}$ & $\begin{array}{c}60.127 \pm 2.731 \\
\mathrm{fg}\end{array}$ \\
\hline $\mathrm{Zn} 2+$ & 1 & $0.127 \pm 0.003 \mathrm{e}$ & $48.821 \pm 0.582 \mathrm{f}$ & $\begin{array}{c}62.003 \pm 1.743 \\
\mathrm{fg}\end{array}$ \\
\hline $\mathrm{Ag}^{+}$ & 1 & $0.124 \pm 0.004 \mathrm{ef}$ & $48.455 \pm 0.412 \mathrm{~g}$ & $\begin{array}{c}60.084 \pm 1.165 \\
\mathrm{fg}\end{array}$ \\
\hline $\mathrm{La} 3+$ & 1 & $0.178 \pm 0.005 \mathrm{bc}$ & $63.106 \pm 0.565 \mathrm{c}$ & $\begin{array}{c}112.076 \pm 3.660 \\
\mathrm{c}\end{array}$ \\
\hline $\mathrm{Ce} 3+$ & 1 & $0.174 \pm 0.003 \mathrm{c}$ & $63.859 \pm 0.368 b c$ & $\begin{array}{c}111.242 \pm 1.887 \\
\mathrm{c}\end{array}$ \\
\hline $\mathrm{Nd} 3+$ & 1 & $0.183 \pm 0.006 \mathrm{~b}$ & $64.836 \pm 0.742 \mathrm{~b}$ & $\begin{array}{c}118.650 \pm 4.783 \\
\text { b }\end{array}$ \\
\hline
\end{tabular}

$* \overline{\mathrm{DW}}$ - dry weight. Data are mean $\pm \mathrm{SE}, \mathrm{n}=4$. Means followed by same letter (s) within same column are not significantly at $\mathrm{P}<0.05$. 
Effects of various organic acids and metal ions dosages on CPT production and plant growth. Figure 1a indicated that the CPT content, CPT yield and plant weight were significantly increased with supplementing maleic acid from 0.05 to $2 \mu \mathrm{mol} / \mathrm{L}$ and reached the peak at with $1 \mu \mathrm{mol} / \mathrm{L}$ maleic acid, resulted in $0.139 \%, 63.327 \mathrm{~g}$ and $86.718 \mathrm{mg} / \mathrm{seedling}$, which were $1.324,1.089$ and 1.418 times of those of the control, respectively.

Malonic acid showed most dramatic enhancement of CPT content, plant growth and CPT production; $0.5 \mu \mathrm{mol} / \mathrm{L}$ malonic acid addition significantly increased CPT content to $0.225 \%$, plant weight to $65.231 \mathrm{~g}$ and CPT production to $144.993 \mathrm{mg} / \mathrm{seedling}$, which were 2.143, 1.122 and 2.371 times of those of the control, respectively (Figure 1b).

Inferior to malonic acid, the additions of malic acid also had good effects on CPT production. Adding $5 \mu \mathrm{mol} / \mathrm{L}$ malic acid enhanced the plant weight to $69.327 \mathrm{~g}$ and CPT yield significantly to $93.869 \mathrm{mg} / \mathrm{seedling}$, which were 1.193 and 1.535 times of those of the control, respectively, although CPT content was slightly improved(Figure 1c).

Treatment with $5 \mu \mathrm{mol} / \mathrm{L} \mathrm{La}^{3+}$ added to the Hoagland nutrition solution, resulted in significant increase of CPT content to $0.186 \%$ and CPT production to 112.059 $\mathrm{mg} / \mathrm{seedling}$, which was 1.771 and 1.832 fold increase over the control, respectively; but it slightly affect the plant growth since the dry weight remained at the same level of 60.752g (Figure 1d).

Similar to $\mathrm{La}^{3+}$, addition of $5 \mu \mathrm{mol} / \mathrm{L} \mathrm{Ce}^{3+}$ to the Hoagland nutrition solution resulted in significant increase of plant weight to $64.627 \mathrm{~g}$ and CPT yield to 106.893 $\mathrm{mg} / \mathrm{seedling}$, which was 1.111 and 1.748 fold higher than that of the control, respectively, whereas the CPT content did not show significant increase (Figure 1e).

$\mathrm{Nd}^{3+}$ treatment did not significantly affect CPT content in all concentrations (Figure 1f). No significant differences in plantlet biomass were observed at any of the concentrations used except when using $5 \mu \mathrm{mol} / \mathrm{L} \mathrm{Nd} 3+$, which resulted in the highest weight. However, $\mathrm{Nd}^{3+}$ additions markedly affected seedlings $\mathrm{CPT}$ yield in all concentrations. The difference was highly significant at the concentration of $5 \mu \mathrm{mol} / \mathrm{L}$, i.e. the CPT yield $111.433 \mathrm{mg} / \mathrm{seedling}$, which was 1.822 fold higher than that of the control.

\section{Discussion}

Data from this study demonstrated that organic acids had significant influences on CPT content, CPT yield and plant growth of C. acuminata, which is consistent with the effects of adding malic acid on those of Catharanthus roseus in suspension cell cultures $^{[20]}$. Organic acids induced accumulation of secondary metabolites might be related to their functions as inhibitors of primary metabolic pathways to stimulate target product biosynthesis. Malonic acid and malic acid are well known competitive inhibitors of succinic dehydrogenase, sequentially they inhibit the tricarboxylic acid (TCA) cycle ${ }^{[21,22]}$. Maleic acid is an inhibitor of proteolytic enzymes that hinders the formation of citric acid ${ }^{[23]}$, so it inhibits the TCA cycle as well.

The reason for changes in CPT content and biomass in the seedlings by the application of heavy metals is not known but it could be related to the effects of metallic cations on the enzymatic activity and carbon metabolism ${ }^{[24]}$. The application of metal irons improved Catharanthus roseus culture conditions for the production of ajmalicine or catharanthine ${ }^{[20]}$, enhanced Saussurea medusa cell culture to produce total flavonoids ${ }^{[13]}$, and maximized the yield for taxol from Taxus spp. cell cultures ${ }^{[12]}$. Metal ions have 
been considered abiotic elicitors or inducing factors ${ }^{[9,11]}$ that trigger the formation of secondary metabolites ${ }^{[25]}$. Adding metal ions to improve secondary metabolite accumulations might be in connection with their effects as prosthetic group of specific enzymes to trigger secondary metabolism ${ }^{[11]}$. It has been reported that elicitor-induced responses and $\mathrm{Ca}^{2+}$ influx can be inhibited by $\mathrm{La}^{3+[26]}$. Our findings also suggest that $\mathrm{La}^{3+}, \mathrm{Ce}^{3+}$, and $\mathrm{Nd}^{3+}$ have elicitor-like effects on secondary metabolite synthesis of $\mathrm{C}$. acuminata.
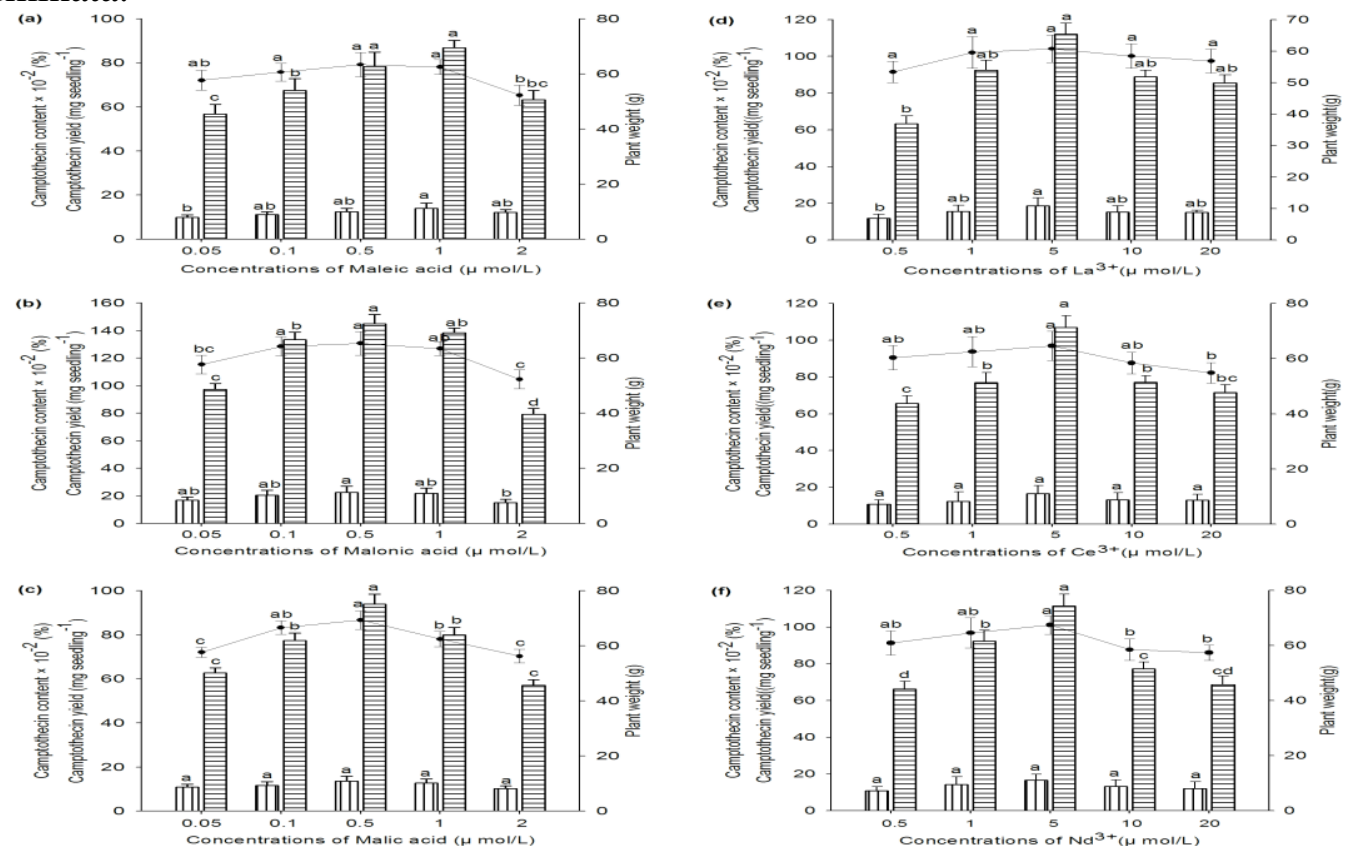

Figure 1. Dosage effects of supplementing of maleic acid(a), malonic acid (b), malic acid.(c), $\mathrm{La}^{3+}$ (d), $\mathrm{Ce}^{3+}(\mathrm{e}), \mathrm{Nd}^{3+}(\mathrm{f})$ to Hoagland's Solution on camptothecin content($(\mathbb{\mathbb { W }})$, plant weight $(\bullet)$ and camptothecin yield( $(\boxminus)$ of $C$. acuminata seedling. Values are means of quadruplicate results and error bars represent standard errors. Different letters on top of bars and curves indicate significant difference $(P<0.05)$.

\section{Conclusions}

The CPT contents and yield were significantly altered with supplementation of organic acids and metal ions. It is suggested that supplementation of organic acids and metal ions to solution is feasible for irrigation of C. acuminata plants and potentially industrially useful improvement of CPT in field culture. Further studies are needed to clarify the relationship between the secondary plant products and organic acids or metal ions.

\section{Acknowledgement}

This research was financially supported by Administration of Traditional Chinese Medicine of Guangdong Province, China(20162030, 20073001), Science and Technology Planning Project of Guangdong Province, China(2015A040404029).

\section{References}

[1] Hsiang Y.H., Hertzberg R., Hecht S.Liu L.F, Journal of Biological Chemistry, 260(1985):14873-14878. 
[2] Douillard J.Y., Cunningham D., Roth A.D., Navarro M., James R.D., Karasek P., Jandik P., Iveson T., Carmichael J.Alakl M, Lancet, 355(2000):1041-1047.

[3] Lorence A. Nessler C.L., Phytochemistry, 65 (2004):2735-2749.

[4] Wall M.E., Wani M.C., Cook C.E., Palmer K.H., McPhail A.T.Sim G.A., Journal of the American Chemical Society, 88(1966):3888-3890.

[5] Liu Z.J.Adams J.C., New Forests, 16(1998):167-175.

[6] López-Meyer M., Nessler C.L.McKnight T.D., Planta Medica, 60 (1994):558-560.

[7] Wiedenfeld H., Furmanowa M., Roeder E., Guzewska J.Gustowski W., Plant Cell Tissue and Organ Culture, 49(1997):213-218.

[8] Mulabagal V.Tsay H.S., International Journal of Applied Science and Engineering, 2 (2004):29-48.

[9] Suvarnalatha G., Rajendran L., Ravishankar G.A.Venkataraman L.V., Biotechnology Letters, 16(1994):1275-1280.

[10]Liu K.H., Ding X.W., Deng B.W.Chen W.Q., Biotechnology Letters, 32(2010):689-693.

[11]Trejo-Tapia G., Jimenez-Aparicio A., Rodriguez-Monroy M., De Jesus-Sanchez A.Gutierrez-Lopez G., Plant Cell Tissue and Organ Culture, 67(2001):19-23.

[12]Wu J., Wang C.Mei X., Journal of Biotechnology, 85 (2001):67-73.

[13] Yuan X., Wang Q., Zhao B.Wang Y., Biotechnology Letters, 24(2002):1889-1892.

[14]Zhong J.J. Wang D.J., Journal of Biotechnology, 46(1996):69-72.

[15]Zhao J., Zhu W.H., Hu Q.He X.W., Biotechnology Letters, 22(2000):1221-1226.

[16] Gaviraj E. N. Veeresham C., Pharmaceutical Biology, 44 (2006):371-377.

[17] Hoagland D. R. Arnon D.I. The water-culture method for growing plants without soil. California Agricultural Experiment Station, 347 (1950):1-31.

[18]Zhao J., Zhu W.H.Hu Q., Biotechnology Letters, 22(2000):825-828.

[19]Zhong J. J. Wang D.J., Journal of Biotechnology, 46(1996):69-72.

[20]Zhao J., Zhu W.H.Hu Q., Biotechnology Letters, 22(2000):825-828.

[21] Bentley L.E. Occurrence of malonic acid in plants. Nature, 170(1952):847 - 848.

[22] Schwartz H.Radler F., Applied Microbiology and Biotechnology, 27(1988):553-560.

[23] Vickery H. B. Palmer J.K., Journal of Membrane Biology (1955):225-239.

[24]Chavan P. D. Karadge B.A., Plant and Soil, 56(1980):201-207.

[25] Verpoorte R., Van der Heijden R., Ten Hoopen H.J.G.Memelink J. Biotechnology Letters, 21(1999):467-479.

[26] Gelli A., Journal of Membrane Biology, 155(1997):35-45. 